following on from unevaluated techniques brought into general use, such as retrolental fibroplasia. For every obstetric intervention she is able to demonstrate adverse effects, yet there is a stubborn and unheeding resistance to change.

If only all obstetricians were compelled to read this book. Even then would they believe it? Would they then comprehend what a serious mistake it is not to understand and respect the normal physiology of labour and birth? Would they then accept wholeheartedly that what a woman needs to birth safely is good emotional support, a tranquil, and unhurried atmosphere, continuity of care and familiar surroundings? Would they then have the humility to know that the only ethical option on their part is what Dr Grantly Dick Read called 'masterly inactivity'? Would they then be willing to share their power with mothers and midwives and permit them to organise the maternity services in a way which not only suits their needs and wishes, but is also the safest?

Fortunately there is increasing evidence that Mrs Tew's views are now being listened to. The Royal Society of Medicine Maternity Forum has accorded her a platform. At the last Active Birth conference at Wembley Conference Centre she was the only one of dozens of eminent speakers to be given a standing ovation. Even those, like the statisticians at the National Perinatal Unit, who question the firmness of some of her conclusions, nevertheless treat her with seriousness and respect. In view of this, is it really ethical to continue unquestioningly our present obstetric-led and hospital-based maternity policy? It is surely time to change to woman and midwife-centred birth care.

HANNA CORBISHLEY Former National Secretary of the National Childbirth Trust.

\section{Organ Transplants and Ethics}

David Lamb, 162 pages, London and New York, $£ 25.00$, Routledge, 1990

This is a contribution to practical moral philosophy which tackles the ethical problems of a whole range of organ transplantation from cadaver and living donors. Brainstem death criteria, which inevitably lead to whole body death, are contrasted with the deontological definitions of the loss of personhood and identity which accompany permanent loss of consciousness. Where brainstem death has not been verified, there may be residual cortical and other areas of the brain which remain alive but are inaccessible to testing. Is such a state compatible with a person, albeit still hanging by a thread? It is cogently argued that the person should be regarded as more than a brain and that respect should be given to the whole body; no attempt should be made to expand the definition of death to include non-cognitive states, however disabling and seemingly irreversible. Further chapters look at the use of fetal tissue for research and transplantation: a strong case is made for the separation of the act of abortion from any desire to obtain tissue. A need still exists to respect the wishes of the mother regarding the disposal of such tissue. With anencephalic infants there are pressures to use organs without waiting for brainstem death. The author sees no reason to change the brain-death criteria for a decerebrate fetus as this may lead to the gradual exploitation of the vulnerable and the brutalisation of society.

Looking at live transplantation, usually between relatives, the loss of a kidney is judged to be less evil than the loss of the full rehabilitation of the patient. Things are more difficult to justify when the potential donor is a minor or incompetent. Non-related gifted live donation is condemned but the consequentialist ethics of not making use of such donation in India are not followed through. One senses the author would justify the death of hundreds of recipients in this area in order to lever the authorities to encourage cadaver donation because there is no alternative.

The equitable distribution of cadaveric organs is considered; should they be regarded as a local, national or international resource? Clearly the hard-to-match recipient benefits from the larger pool of donors but equally there should be some recompense for those who have raised the donation rate locally. The unsatisfactory state of the donor card situation in the UK is emphasised, a point already stressed by Ian Kennedy; the alternatives of an opting-out register and a reduction in the power of veto by the relatives over the previously declared wishes of the donor are highlighted.

This is an excellent summary of the present situation, well researched with a full bibliography. It contains cogent arguments against the headlong adoption of consequentialist ethics in this important area of medicine.

VICTOR PARSONS

Honorary Senior Lecturer,

Department of Medicine,

King's College Hospital, London.

\section{Torture Survivors - a New Group of Patients}

L Jacobsen and $P$ Vesti, 80 pages, Copenhagen, $£ 12.00$, The Danish Nurses Organisation, 1990

Torture is a standing reproach to those who believe in the innate goodness of man. It is a constant reminder of the depths of human wickedness and depravity. Neither is there any valid evidence that things are getting better. Although historical comparisons are fraught with difficulty, there is good reason to suppose that torture is becoming more, rather than less, common. It is being used in a third of the nations of the world. It is documented in all but one of the six continents, including Europe. The methods used are, if anything, increasing in horror and it is undeniable that doctors and other health-care workers are actively participating in the process. Few have so far been punished even when vicious regimes are finally overthrown, so that there are few effective deterrents. Some doctors even claim that, since they have not formally affirmed an ethical code, they have no obligation to obey one.

The main purpose of torture is to control the population through the use of terror. Perhaps this was always so. Was the Inquisition really concerned with the heresy of an individual or was it more interested in maintaining the faith of the whole community? In these terms the individual victim becomes unimportant. The purpose is to dehumanise him or her (women are also tortured and even more abominably so). Because of the involvement of doctors and nurses, contrary to almost all the available ethical codes from antiquity, there is a responsibility for them to understand and to be knowledgeable about the existence and practice of torture. A small number take a specialist interest in rehabilitating the survivors. It is a remarkable testimony to the powers of recovery of the human soul that such rehabilitation has a reasonable chance of success.

This helpful and eminently readable 
little book describes the work of the pioneering rehabilitation centre in Copenhagen. It provides a helpful guide to those developing an interest in the subject. It also provides useful information for all health professionals and should be required reading for every medical and nursing student. The horrors it describes and illustrates are not for the faint-hearted, but sadly torture will not go away because we ignore it. On the contrary, such an attitude creates the very atmosphere in which it is more likely to thrive. Although written by a nurse, there is great emphasis upon a team approach but the duties of individual team members are not set out in detail. It is not always easy to understand the contribution which particular professional skills make to the overall outcome, although the importance of working together and moving the survivor from a position of total dependence to one in which she/he is prepared to assume control over her/his own life and rehabilitation programme, are well brought out.

The book would have benefited from a 'word wash' by a native English speaker, since the nuances are sometimes difficult to understand. Those who are prepared to make the effort to discover them will be richly rewarded.

J STUART HORNER Member, Torture Working Party, British Medical Association

[See also the supplement published with this issue of the journal. Editor.]

\section{The Abuse of Casuistry: A History of Moral Reasoning}

Albert $\mathbf{R}$ Jonsen and Stephen Toulmin, 429 pages, Berkeley and Los Angeles, US\$14.95, University of California Press, 1988

Give a certain kind of dog a bad name and, with a bit of luck, you might succeed in persuading the government to introduce legislation against that particular breed. At a later stage, members of a certain school of thought - perhaps more than one school - might convince the government that such legislation was inappropriate for some reason. They might even convince the government of the breed's innocence. So much for dogs, but what happens when it is a school of thought that gets the bad name?

Casuistry has had a bad name for quite a long time, and Jonsen and Toulmin believe it is time to put the record straight. The peculiar task of their book, as they put it, is not to rehabilitate the word but rather the art to which the word 'casuistry' refers: 'the practical resolution of particular moral perplexities, or "cases of conscience". They note that in recent times it has again become acceptable to discuss specific circumstances and cases. This state of affairs, they feel, has come about almost inadvertently as a byproduct of our preoccupation with professional ethics, notably medical ethics. However, although we can see a new casuistry at work in arguments advanced about various issues, 'the philosophical disrepute into which "case ethics" has fallen means that the forms and methods proper to such arguments are not widely discussed or understood'.

The authors make a notable contribution towards filling this gap. Whilst tracing the roots of casuistry in antiquity, and giving an ample history of the subject, they succeed in covering in some depth various arguments about the difference between the kind of reasoning used in geometry and that practical reasoning involved in ethics. They also provide ample descriptions and analyses of how the casuists worked. Whilst admitting that there was at times a fair amount of misuse of the art, they hold that Pascal's famous attack upon it in The Provincial Letters went too far because he attacked casuistry as a whole instead of merely trying to rectify its misuse. In their opinion, the abuse of casuistry - in the sense of the scorn that has been poured on it since Pascal's time - has been almost entirely unjustified.

As for the present day, they ask how there can be a renewed casuistry in a culture which lacks the necessary institutions. Some of these institutions, they believe, have come into existence, notably in the world of bioethics. Although much of what they say in this regard refers specifically to the United States, it should be clear to those actively involved in bioethics that somewhat similar things could be said about other parts of the world.

There are numerous discussions of bioethical issues in this book. Indeed the very occasion that led to its being written was the authors' involvement in the work of The National Commission for the Protection of Human Subjects of Biomedical and Behavioral Research in the United States, an outcome of that work having been a casuistry for distinguishing acceptable and unacceptable ways of involving people as subjects in medical or behavioural research. The book should therefore be of enormous interest to anyone with a serious interest in bioethics or, indeed, any other branch of ethics.

BERNARD HOOSE

Research Fellow in Christian Ethics, Heythrop College, 11-13 Cavendish Square, London WIM OAN.

\section{Proceed with Caution: Predicting Genetic Risks in the Recombinant DNA Era}

Neil A Holtzman, 303 pages, Baltimore and London, $£ 23.50 \mathrm{hc}, £ 9.55 \mathrm{sc}$, Johns Hopkins University Press, 1989

Neil Holtzman is Professor of Pediatric at the Johns Hopkins University Schoo of Medicine and has special interests ir the management of inborn errors of metabolism and in the education of the public and of doctors. The concept of this book arose out of a report in the mid-1980s on genetic susceptibilities to environmental agents.

For description it is useful to divide the book into three main parts. In the introduction the scope of the book is summarised and the principles of inheritance and of the role of genes in disease are taught (chapters 1 to 3,56 pages). Then follow three chapters dealing with the new genetics and based largely on DNA techniques (pages 57 to 138). The sixth chapter describes the transfer of technology from research to clinical and commercial application. The last three chapters cover the factors involved in the development of widespread genetic screening, discussions of the philosophy of genetic testing, 'In whose best interest', and 'What is going to be done?'.

First let me say how appropriate such a publication is and what a wealth of information Holtzman has collected. He writes in an idiosyncratic style but is very readable. At the end of the book many references are given along with copious notes and a huge sprinkling of personal communications which would be difficult to check. In covering such a wide field, Holtzman has often cut 